Arq. Bras. Med. Vet. Zootec., v.70, n.6, p.1691-1698, 2018

\title{
Avaliação proteica do humor aquoso de equinos
}

\author{
[Evaluation of equine aqueous humor protein] \\ P.D. Galera ${ }^{1}$, L.R. Silva ${ }^{1}$, M.P. Fonseca ${ }^{1}$, A.P. Oriá ${ }^{2}$, W. Fontes ${ }^{1}$ \\ ${ }^{1}$ Universidade de Brasília - Brasília, DF \\ ${ }^{2}$ Universidade Federal da Bahia - Salvador, BA
}

\begin{abstract}
RESUMO
A avaliação proteica do humor aquoso (HA) pode ser utilizada como método diagnóstico nas uveítes. Entretanto, estudos sobre as proteínas nesse fluido, em equinos hígidos, são escassos e apresentam variações conforme a metodologia empregada. Dessa forma, objetivou-se realizar a análise proteica e citológica do HA nessa espécie, bem como verificar sua correlação com as proteínas plasmáticas. Foram avaliados 13 equinos adultos (26 olhos), sem raça definida, machos ou fêmeas. Mediante aqueocentese, foi coletado $0,5 \mathrm{~mL}$ de humor aquoso de cada olho. Cada amostra foi encaminhada para quantificação proteica pelo método de Bradford modificado e pela eletroforese em gel de poliacrilamida - dodecil sulfato de sódio (SDS-PAGE), bem como para avaliação citológica. Por meio de venopunção, coletou-se sangue para determinação da concentração de proteínas séricas. Treze olhos (50\% das amostras) apresentaram valor proteico médio de $40,3 \mathrm{mg} / \mathrm{dL} \pm 6,45$ e a eletroforese demonstrou presença de proteínas de massas mais elevadas que $43 \mathrm{KDa}$. Houve ausência de células em 96,15\% das amostras ( 25 olhos). Equinos hígidos apresentaram baixa concentração de proteínas no HA. Já a correlação entre proteína no humor aquoso/proteína plasmática total foi de $0,56 \%$.
\end{abstract}

Palavras-chave: aqueocentese, citologia, proteínas, cavalo

\begin{abstract}
Evaluation of equine aqueous humor (AH) proteins can help the diagnosis of uveitis. However, studies on proteins in this fluid in healthy horses are scarce and present variations according to the methodology employed. This study aimed to perform protein analysis and cytology of equine aqueous humor of healthy horses and verify its correlation with plasmatic proteins. Thirteen adult horses (26 eyes), mixed breed, male or female were evaluated. A volume of $0.5 \mathrm{~mL}$ of aqueous humor was collected through aqueocentesis from both eyes. The samples were submitted to protein quantification by modified Bradford method and to sodium dodecyl sulphate - polyacrylamide gel electrophoresis (SDS-PAGE), and to cytological evaluation. Blood was collected for determination of plasmatic protein concentration. Thirteen eyes (50\% of the samples) had values larger than zero by the Bradford method, with an average of $40.3 \mathrm{mg} / \mathrm{dl} \pm 6.45$. Electrophoresis showed presence of higher masses of proteins $(43 \mathrm{KDa})$. There were no cells in $96.15 \%$ of the samples (25 eyes). Healthy equines presented low protein concentration in the HA. The ratio between protein concentration in the aqueous humor / total plasma protein of $0.56 \%$.
\end{abstract}

Keywords: aqueous humor, proteins, horse

\section{INTRODUÇÃO}

O HA é o fluido incolor que preenche o segmento anterior do bulbo do olho, responsável pelo suporte trófico e pela remoção de metabólitos da córnea e da lente, uma vez que

Recebido em 19 de junho de 2017

Aceito em 3 de novembro de 2017

E-mail: paulaeye@unb.br ambas são avasculares. Por se tratar de um meio transparente, esse fluido também proporciona um índice de refração apropriado entre a córnea e a lente (Goel et al., 2010; Gabelt e Kaufman, 2011; Gilger e Stoppini, 2011).

O HA é formado a partir do sangue por três mecanismos: difusão, ultrafiltração e secreção 
ativa pelo epitélio do corpo ciliar (Gum e Mackay, 2013). Sua baixa viscosidade decorre principalmente da grande quantidade de água $(99,6 \%)$ e do baixo teor proteico (Goel et al., 2010; Gabelt e Kaufman, 2011). A drenagem pela via uveoescleral depende da espécie e considera-se que tenha maior importância em equinos, já que, nos cães e nos seres humanos, a drenagem é realizada principalmente por meio do ângulo iridocorneal (Van der Woerdt et al., 1995).

A composição bioquímica do HA tem sido alvo de diversos estudos (Millar et al., 2006; Goel et al., 2010; Gabelt e Kaufman, 2011; Gum e Mackay, 2013). Por ser o humor aquoso um ultrafiltrado do plasma, sua composição assemelha-se a ele, com algumas exceções notáveis, como baixa concentração proteica, quantidades reduzidas de glicose, ureia $\mathrm{e}$ nitrogênio não proteico e elevada concentração de ascorbato e lactato (Gabelt e Kaufman, 2011; Gilger e Deeg, 2011).

O aumento de proteínas e de células no HA pode ser desencadeado pela desestabilização da barreira hematoaquosa (BHA), considerada reversível, se mediada por receptores, ou irreversível, quando secundária a alterações anatômicas. Pode decorrer de uveítes, intervenções cirúrgicas ou paracentese, por exemplo (Albaugh et al., 2011). O insulto traumático estimula a contração das células endoteliais do corpo ciliar, o que induz ao extravasamento de proteínas do leito vascular (Khrone et al., 1995). O estudo do HA de equinos pode ser adjutório ao diagnóstico e pode auxiliar em tratamentos precoces (Gilger, 2013; Linn-Pearl et al., 2014), a exemplo da uveíte recorrente equina (Gilger e Deeg, 2011).

Amostras do HA são adquiridas por meio da aqueocentese e podem ser encaminhadas para exames distintos, como citologia, sorologia, quantificação proteica, cultura bacteriana, titulação de anticorpos e PCR (Gilger e Deeg, 2011). A citologia do humor aquoso é auxiliar ao diagnóstico de infecções ou de processos neoplásicos e consiste na contagem de células totais, seguida pela sedimentação do fluido para realização do esfregaço ou preparação com fixador próprio (Young, 2007). Já os métodos de Bradford e a eletroforese em gel são empregados para a quantificação proteica (Bradford, 1976; Bollag et al., 1996; Grus et al., 2007).

Embora haja descrição da concentração proteica do HA de equinos hígidos (Hazel et al., 1985; Gum e Mackay, 2013), verifica-se a escassez da padronização metodológica, o que dificulta a interpretação dos resultados. Dessa forma, objetivou-se mensurar a concentração das proteínas do humor aquoso de cavalos saudáveis e correlacioná-la com a concentração de proteínas plasmáticas. Ainda, pretendeu-se avaliar a citologia desse fluido.

\section{MATERIAL E MÉTODOS}

Esta pesquisa foi submetida e aprovada pelo Comitê de Ética no Uso Animal (protocolo $\mathrm{n}^{\mathbf{0}}$ 50973/2010). Foram incluídos, neste estudo, 13 equinos adultos (26 olhos), sete machos castrados e seis fêmeas, sem raça definida e com massa corpórea entre 356 e 515 kg $(447,8 \pm 47,9 \mathrm{~kg})$, provenientes do Hospital Veterinário. Os animais foram submetidos à avaliação clínica rotineira e coleta de sangue venoso para exames laboratoriais, para confirmação do estado de higidez. Dez mililitros de sangue foram obtidos da veia jugular, sendo a amostra dividida em dois tubos, um com anticoagulante para o hemograma, análise de fibrinogênio e proteína plasmática total por densitometria, e outro sem anticoagulante, do qual se extraiu o soro para as análises bioquímicas de albumina, proteína total, creatinina, ureia, aspartato aminotransferase e gamaglutamiltransferase.

Seguiu-se semiotécnica oftálmica para que se descartassem alterações oculares, mediante avaliação dos reflexos pupilares, biomicroscopia com lâmpada em fenda (SL-15®, Kowa, Califórnia, EUA), teste da lágrima de Schirmer (Teste de Schirmer ${ }^{\circledR}$, Ophthalmos - São Paulo, SP), oftalmoscopia binocular indireta (Oftalmoscópio binocular indiretoEytec, São Paulo, Brasil), prova da fluoresceína (Fluoresceína Strips ®, Ophthalmos - São Paulo, $\mathrm{SP})$ e tonometria de aplanação $\left(\right.$ Tono $\mathrm{Pen}^{\circledR} \mathrm{XL}$, Medtronic, Flórida, EUA).

Os animais foram submetidos à contenção física em brete, seguida por sedação com xilazina $10 \%$ (Sedomin®, Laboratórios König S.A., Avellaneda, Argentina), na dose de $1,0 \mathrm{mg} / \mathrm{kg}$, 
por via intravenosa. O nervo auriculopalpebral foi bloqueado bilateralmente, com o uso de $10 \mathrm{~mL}$ de cloridrato de lidocaína a $2 \%$ sem vasoconstritor (Xylestesin ${ }^{\circledR}$, Cristal Pharma Ltda., Minas Gerais, Brasil), conforme descrito por Muir e Hubbell (2009). Após a constatação da acinesia palpebral, realizou-se antissepsia ocular com solução de polivinil pirrolidona iodo a $1 \%$, seguida da anestesia tópica com cloridrato de proximetacaína $0,5 \%$ (Anestalcon ${ }^{\circledR}$, Alcon Laboratórios do Brasil Ltda., São Paulo - SP, Brasil). Ato contínuo, executou-se a aqueocentese em região próxima ao limbo e paralela ao plano da íris, com a utilização de agulha hipodérmica $13 \times 4,5$ acoplada a uma seringa de $1 \mathrm{~mL}$ (Galera et al., 2009). Foi coletado $0,5 \mathrm{~mL}$ de HA de cada olho, sendo $0,25 \mathrm{~mL}$ encaminhado para imediata análise citológica e o remanescente armazenado em microtubos de polipropileno (Eppendorf), sob refrigeração de $-20^{\circ} \mathrm{C}$, por até três dias, para a posterior mensuração proteica.

Após o procedimento, foram instiladas duas gotas de sulfato de atropina $1 \%$ (Atropina ${ }^{\circledR}$ colírio, $5 \mathrm{~mL}$, Allergan Laboratórios do Brasil Ltda.), a cada oito horas, e duas gotas de colírio de tobramicina $0,3 \%$ (Tobrex ${ }^{\circledR}$ colírio, $5 \mathrm{~mL}$, Alcon Laboratórios do Brasil Ltda.), a cada seis horas, por três dias consecutivos. Os animais foram observados durante sete dias consecutivos, e não foram observadas alterações oculares.

O HA foi centrifugado e colocado sobre lâmina de microscopia, para a preparação do esfregaço. Após, realizou-se coloração com panótico (Instant Porv ${ }^{\circledR}$ ), de acordo com as recomendações do fabricante. As lâminas foram examinadas, posteriormente à secagem, com a utilização de óleo de imersão no aumento de 100x.

A análise proteica do HA foi realizada pelo método de Bradford (Bradford, 1976) modificado, com a utilização do comprimento de onda de $595 \mathrm{~nm}$. A concentração de proteínas foi estabelecida de acordo com a absorbância da amostra e sua posterior substituição na equação da curva padrão. Para a preparação da solução reagente de Bradford, utilizou-se álcool etílico (95\%), ácido fosfórico (85\%) e Commassie blue G250. Foram dissolvidos $350 \mathrm{mg}$ de Comassie G250 em $100 \mathrm{~mL}$ de etanol $95 \%$ e adicionaramse $200 \mathrm{~mL}$ de ácido fosfórico 88\%, formando-se, assim, a solução de estoque, que foi armazenada no escuro. A solução de trabalho foi formada com 42,5 mL de água milli-Q, 1,5 mL de etanol $95 \%, 3 \mathrm{~mL}$ de ácido fosfórico $88 \%$ e $3 \mathrm{~mL}$ da solução de estoque. A BSA (albumina sérica bovina) foi utilizada na concentração de $2 \mathrm{mg} / \mathrm{mL}$, e o $\mathrm{HCl}$ (ácido clorídrico) a 0,1 M.

Pipetaram-se 3, 5, 10, 15, 20 e $25 \mu \mathrm{L}$ de BSA, com acréscimo de, respectivamente: $87,85,80$, 75,70 e $65 \mu \mathrm{L}$ de água Milli-Q e $10 \mu \mathrm{L}$ de $\mathrm{HCl}$ em Eppendorfs, de forma a se obterem as concentrações finais de $0,06,0,1,0,2,0,3,0,4$ e $0,5 \mu \mathrm{g} / \mu \mathrm{L}$. A solução do branco foi composta por $90 \mu \mathrm{L}$ de água Milli-Q e $10 \mu \mathrm{L}$ de $\mathrm{HCl}$. A solução das amostras de HA foi composta por $10 \mu \mathrm{L}$ de cada amostra, $30 \mu \mathrm{L}$ de água Milli-Q e $10 \mu \mathrm{L}$ de $\mathrm{HCl}$. As amostras foram previamente descongeladas e centrifugadas a $14.000 \mathrm{rpm}$, durante 10 minutos.

Em seguida, retirou-se uma alíquota de $10 \mu \mathrm{L}$ de cada Eppendorf, que foi transferida para a placa, sendo depositada em seu poço correspondente. A cada poço, foram adicionados $300 \mu \mathrm{L}$ do reagente de Bradford previamente preparado. Decorridos 15 minutos de incubação no escuro, seguiu-se leitura em espectrofotômetro utilizando-se absorvância de $595 \mathrm{~nm}$. Com base nos valores de absorvância mensurados em triplicata (Bradford, 1976), confeccionou-se um gráfico de dispersão de concentração versus absorvância, no programa $\operatorname{Excel}^{\circledR}(2013)$, obtendo-se um valor de equação da reta para as medidas referentes à BSA, que foi utilizada para quantificação das proteínas totais de humor aquoso. A concentração de proteínas plasmáticas totais (PT) (g/dL) foi determinada com auxílio de um refratômetro.

Para a utilização dos géis de poliacrilamida dodecil sulfato de sódio (SDS-PAGE), preparados a $12 \%$, aplicou-se o sistema de placas Hoefer SE 600 series electrophoresis unit (Pharmacia Biotech), o qual foi imerso em tampão TRIS-Glicina $\mathrm{pH} 8.8$, a uma temperatura de $19{ }^{\circ} \mathrm{C}$ controlada pelo aparelho de refrigeração Multitemp II Cooling Bath (Amersham Biosciences), e submetido a uma fonte elétrica com corrente constante de $20 \mathrm{~mA}$ e voltagem máxima de $300 \mathrm{~V}$.

As amostras foram centrifugadas durante 10 minutos a $14.000 \mathrm{rpm}$. Utilizaram-se $30 \mu \mathrm{L}$ de 
cada amostra, ressuspendidos em $30 \mu \mathrm{L}$ de solução tampão (Tris-HCl $125 \mathrm{mmol}$; azul de bromofenol $0,01 \%$; sacarose $20 \%$; SDS $4,0 \%$ e DTT $100 \mathrm{mmol}$ ), e as amostras foram, então, aquecidas durante 10 minutos a $94^{\circ} \mathrm{C}$. Posteriormente, elas foram aplicadas nos poços do gel, em um pente de 20 poços com capacidade de $100 \mu \mathrm{L}$ cada. Os géis foram corados com prata de alta sensibilidade, como descrito em Teles et al. (2012). Resumidamente, os géis foram submetidos a etapas de fixação com ácido tricloroacético $12 \%$ e metanol $50 \%$ por uma hora; uma segunda fixação foi realizada após uma hora, por incubação com ácido acético $5 \%$ e etanol $50 \%$. O gel foi lavado com água Milli-Q por cinco minutos, em dois ciclos.

Seguiu-se incubação do gel com a solução de coloração de prata por 20 minutos, lavagem com água Milli-Q. Ato contínuo, procedeu-se à revelação da prata com uma solução de revelação contendo $0,017 \%$ de ácido cítrico e $0,236 \%$ de formaldeído. Em seguida, o gel foi imerso na solução de parada da revelação (30\% de etanol, $7 \%$ de ácido acético e $2,5 \%$ de glicerol $87 \%$ ), onde permaneceu por 20 minutos, e, para finalizar a coloração, adicionou-se sobre o gel a solução de hidratação com $28.5 \%$ de etanol e $2,175 \%$ de glicerol.

Os géis foram digitalizados com o scanner Image scan UMAX GE, cujas imagens geradas foram armazenadas em modo TIFF em tons de cinza e modo JPG colorida. As imagens do formato TIFF foram encaminhadas para o software ImageJ (Schneider et al., 2012), versão 1.50i, e foram submetidas à análise por densitometria, de forma a se medir a densidade óptica relativa, considerando-se todas as bandas presentes em cada poço de forma aditiva. A densidade óptica de cada poço foi normalizada em relação ao maior valor obtido.

Os valores de concentração de proteínas obtidos pelo teste de Bradford foram tabulados, avaliados quanto à normalidade (teste de KolmogorovSmirnov) e quanto à correlação entre os valores de proteínas plasmáticas e proteínas do HA, calculando-se a correlação de Pearson. O intervalo de confiança adotado foi de 95\%, baseado na transformação de Fisher. As amostras também foram avaliadas quanto a diferenças entre os olhos direito e esquerdo (teste $t$ de
Student de duas caudas, pareado) e entre os grupos macho e fêmea (teste $t$ de Student para amostras independentes de igual variância).

\section{RESULTADOS}

Ao exame citológico, verificou-se ausência de células em 96,15\% das amostras (25 olhos) de HA, e em um olho $(3,95 \%)$ observou-se a presença de um melanócito repleto de grânulos de melanina.

Das 26 amostras de humor aquoso quantificadas pelo método de Bradford modificado, apenas 13 amostras (50\%) tiveram valores diferentes de zero. Nessas amostras, o valor proteico médio obtido foi de $40,3 \pm 6,45 \mathrm{mg} / \mathrm{dL}$ (min: 32,43mg/dL; máx: $52,0 \mathrm{mg} / \mathrm{dL}$ ), sendo as médias de $39,05 \mathrm{mg} / \mathrm{dL} \pm 5,32$ e $41,37 \mathrm{mg} / \mathrm{dL} \pm 7,52$ para olhos direito e esquerdo, respectivamente.

Observou-se ainda, dentre as amostras que tiveram valores proteicos diferentes de zero, a razão de $0,56 \%$ entre os valores médios de proteína no humor aquoso (HA)/proteína plasmática total (PPT), observando-se distribuição normal dos valores e correlação de Pearson negativa moderada $\left(\rho=-0.64, \quad R^{2}\right.$ linear $=0.41$, 95\% CI -0.97 a 0.55) (Mukaka, 2012) ao se comparar a concentração de proteínas plasmáticas totais à concentração média de proteínas do HA de ambos os olhos, dosada pelo método de Bradford (Fig. 1). As comparações entre os olhos direito e esquerdo e entre machos e fêmeas não se mostraram significativas $(\mathrm{P}>0.05)$

A produção do gel SDS-PAGE possibilitou a separação das proteínas presentes no HA de equinos por massa molecular, demonstrando visualmente uma variação na distribuição proteica de indivíduo para indivíduo, e variações entre olhos direito e esquerdo em um mesmo indivíduo, como se observa nos indivíduos 6 e 7 (Fig. 2). Verificou-se, também, que a maioria das bandas com elevada densidade óptica se encontra na região de massas acima de $43 \mathrm{KDa}$. A Fig. 2 representa o perfil eletroforético de proteínas de cada animal, em que de 5 a 8 , há diferentes equinos hígidos, e as letras D e E representam, respectivamente, o olho direito e o olho esquerdo de cada animal. 
Avaliação proteica...

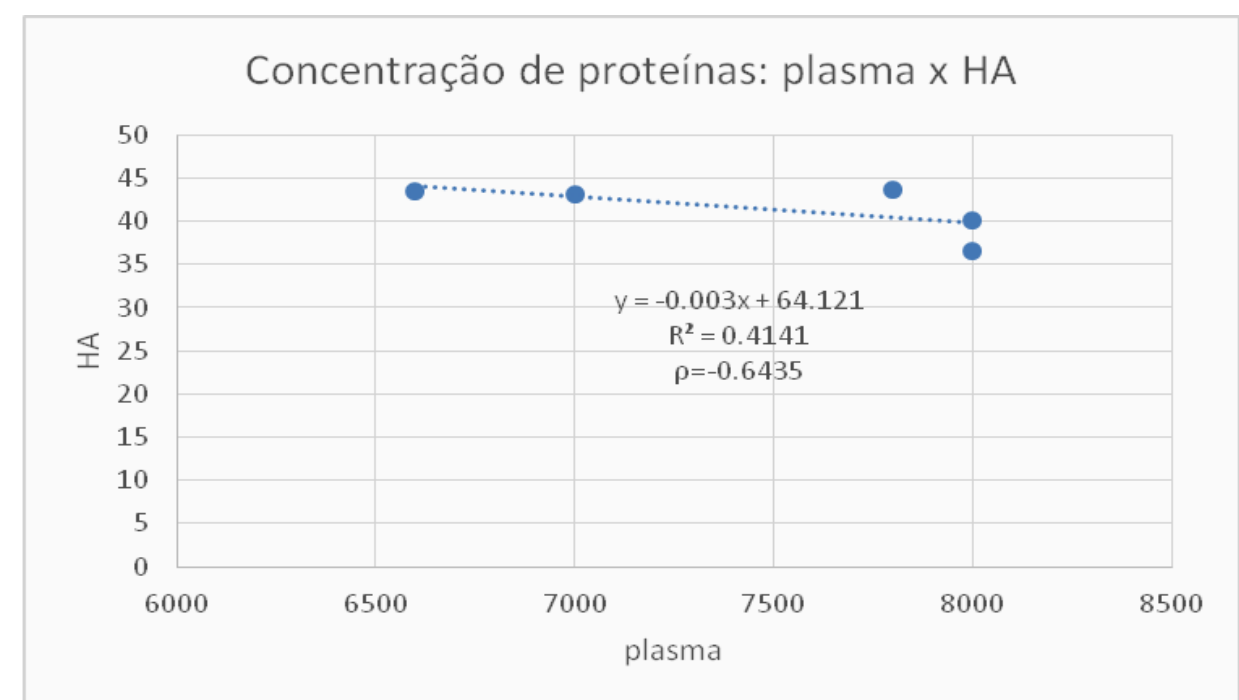

Figura 1. Curva de regressão linear entre a concentração de proteínas plasmáticas totais e a concentração média de proteínas no HA de ambos os olhos.

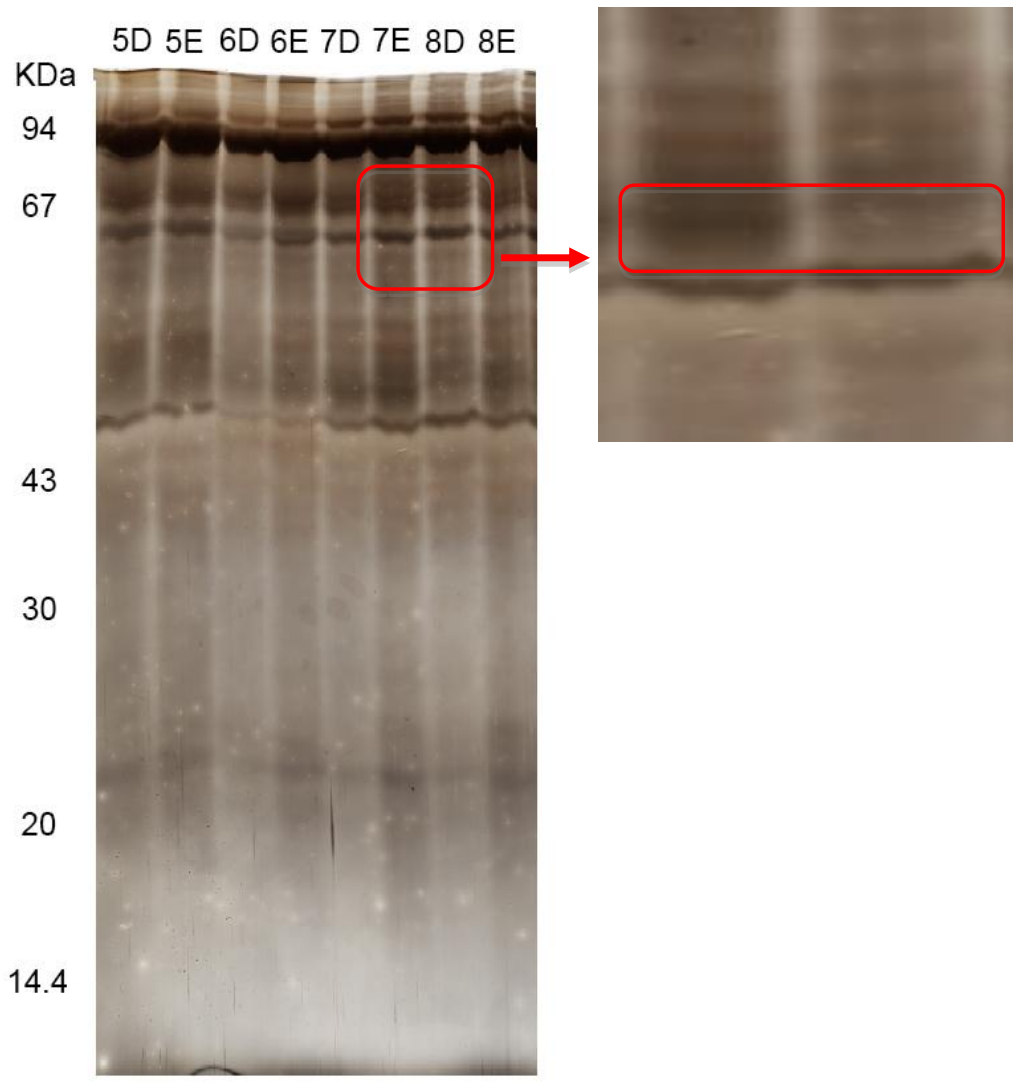

Figura 2. Perfil eletroforético de proteínas do humor aquoso de diferentes animais em gel SDS-PAGE a $12 \%$, demonstrando visualmente uma variação na distribuição proteica de indivíduo para indivíduo e em um mesmo indivíduo variando de um olho para outro. O inserto destaca a diferença entre os indivíduos 7 e 8, observando-se uma banda intensa no indivíduo 7, com intensidade muito menor no indivíduo 8 . Os valores à esquerda correspondem às posições dos marcadores de massa molecular no gel. 
A avaliação dos géis por densitometria mostrou que também há considerável variação no total de proteínas entre os indivíduos. Em geral, a concentração de proteínas é semelhante entre os olhos do mesmo indivíduo, com algumas exceções. A Fig. 3 mostra o perfil densitométrico normalizado das proteínas de HA dos olhos incluídos no estudo.

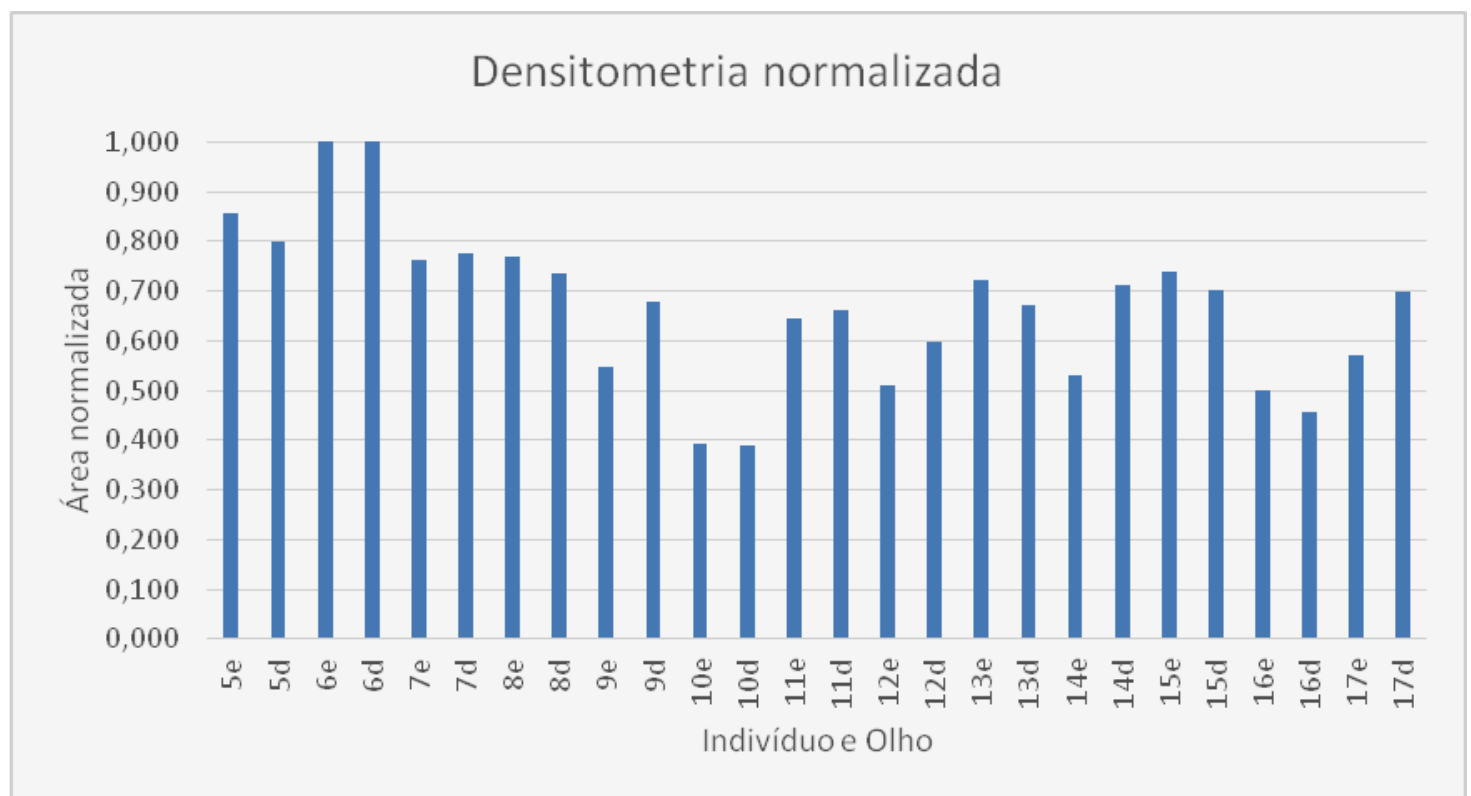

Figura 3. Densitometria de proteínas do HA dos olhos avaliados neste estudo. As barras indicam a área normalizada medida por densitometria do total de proteínas em cada poço do gel de eletroforese. Os números sob cada barra indicam o número do animal e as letras $\mathrm{D}$ e E representam o olho direito e o esquerdo, respectivamente.

Os valores médios de proteínas plasmáticas totais (PPT), calculados com o refratômetro, foram de $7,29 \mathrm{~g} / \mathrm{dL} \pm 0,51$. Já a análise de proteína total teve como resultado a média de 7,76 $\mathrm{g} / \mathrm{dL} \pm 0,82 \mathrm{e}$ a albumina resultou em uma média de 2,28 g/dL $\pm 0,43$.

\section{DISCUSSÃO}

A análise do humor aquoso tem sido preconizada no diagnóstico de uveítes, a despeito de a aqueocentese não ser isenta de riscos (Featherstone e Heinrich, 2013; Wiggans et al., 2014). A fim de se minimizar a desestabilização da barreira hematoaquosa, utilizou-se agulha com menor calibre e instilação de atropina $1 \%$ após a punção (Albaugh et al., 2011).

O exame citológico do humor aquoso deve revelar um padrão acelular, uma vez que é um fluido com baixo teor proteico, e, ocasionalmente, podem ser observados grânulos livres de melanina ou melanócitos (Hazel et al., 1985; Young, 2007). Resultados semelhantes foram observados, verificando-se ausência de células em $96,15 \%$ das amostras (25 olhos).

A avaliação proteica pelo método de Bradford resultou na leitura de metade das 26 amostras de HA avaliadas, uma vez que o restante das amostras apresentou valor proteico igual a zero, possivelmente pelo fato de a quantidade de proteína da amostra estar abaixo da sensibilidade do método de Bradford. Utilizou-se curva padrão variando entre 6 e 50 microgramas, e 13 amostras apresentaram leituras abaixo até mesmo da absorbância do branco do método, acarretando a perda da linearidade. Assim, estes valores não foram considerados e foram normalizados a zero.

Entretanto, mediante eletroforese em gel poliacrilamida, foi possível observar proteínas nessas amostras, por coloração com prata, evidenciando-se bandas proteicas mesmo nas amostras quantificadas pelo teste de Bradford modificado como zero. A eletroforese é um método de custo acessível, reprodutível e rápido para a quantificação e visualização do perfil 
proteico, que separa as proteínas conforme sua massa molecular (Bollag et al., 1996; Grus et al., 2007), mostrando ser mais sensível que o método de Bradfod.

Descrições prévias reportam concentração proteica do humor aquoso de equinos hígidos entre 10-50 mg/dL (Hazel et al., 1985; Gum e Mackay, 2013), com métodos que diferem entre si, dificultando a comparação dos valores de proteína do humor aquoso.

O valor médio das PPT foi de 7,76 g/dL $\pm 0,82$, semelhante ao descrito em literatura, de $6,9 \mathrm{~g} / \mathrm{dL} \pm 0,4$ (Boscan et al., 2007). A concentração proteica do humor aquoso geralmente é 200 vezes inferior à concentração proteica plasmática (Townsend, 2008), conforme verificado neste trabalho, cujo valor médio da porcentagem de proteína no humor aquoso (HA) em relação ao valor da proteína plasmática total (PPT) foi $0,56 \%$.

\section{CONCLUSÃO}

Neste estudo, são sugeridos valores de referência para concentração proteica do humor aquoso de equinos pelo método de Bradford. A maioria das bandas proteicas situou-se acima de $43 \mathrm{KDa}$, por meio da eletroforese, e este método detectou proteínas em amostras não lidas pelo método de Bradford. Verificou-se, ainda, ser a aqueocentese um procedimento viável economicamente e de baixo risco, que pode ser empregada para corroborar o diagnóstico de afecções oculares em equinos.

\section{REFERÊNCIAS}

ALBAUGH, R.A.; ROUSH, J.K.; RANKIN, A.J. et al. Fluorophotometric and tonometric evaluation of ocular effects following aqueocentesis performed with needles of various sizes in dogs. Am. J. Vet. Res., v.72, p.556-561, 2011.

BOLLAG, D.M.; ROZYCKI, M.D.; EDELSTEIN, S.J. Gel electrophoresis under non denaturing conditions. In: BOLLAG, D.M.; ROZYCKI, M.D.; EDELSTEIN, S.J. (Eds.). Protein methods. 2.ed. New York: John Wiley \& Sons, 1996. p.155-172.

BOSCAN, P.; WATSON, Z.; STEFFEY, E.P. Plasma colloid osmotic pressure and total protein trends in horses during anesthesia. Vet. Anaesth. Analg., v.34, p.275-283, 2007.

BRADFORD, M.M. A rapid and sensitive method for the quantification of microgram quantities of protein utilizing the principle of protein-dye binding. Anal. Biochem., v.72, p.248-254, 1976.

FEATHERSTONE, H.J.; HEINRICH, C.L. Ophthalmic examination and diagnostic procedures. Part 1: the eye examination and diagnostic procedures. In: GELATT, K.N.; GILGER, B.C.; KERN, T.J. (Eds.). Veterinary ophthalmology. 5.ed. Iowa: John Wiley \& Sons, 2013. p.533-613.

GABELT, B.T.; KAUFMAN, P.L. Production and flow of aqueous humor. In: LEVIN, L.A.; NILSSON, S.F.E.; VER HOEVE, J.; WU, S.M. (Eds.). Adler's physiology of the eye. 11.ed. Edinburgh: Elsevier, 2011. p.274-307.

GALERA, P.D.; LAUS, J.L.; SOARES, A.M.B. et al. Avaliação dos efeitos da flunixina meglumina, por via subconjuntival, sobre a concentração e padrão proteico do humor aquoso de cães submetidos à paracentese da câmara anterior. Ciênc. Anim. Bras. v.4, p.1310-1316, 2009.

GILGER, B. Equine ophthalmology. In: GELATT, K.N. Veterinary ophthalmology. 5ed. Philadelphia: Blackwell Publishers, 2013. p.1560-1609.

GILGER, B.C.; DEEG, C. Equine recurrent uveitis. In In: GILGER, B.C. (Ed.). Equine ophthalmology. 2.ed. St. Louis: Elsevier Saunders, 2011. p.317-340.

GILGER, B.C.; STOPPINI, R. Equine ocular examination: routine and advanced diagnostic techniques. In: GILGER, B.C. (Ed.). Equine ophthalmology. 2.ed. St. Louis: Elsevier Saunders, 2011. p.1-36.

GOEL, M.; RENATA G.P.; LEE, R.K. et al. Aqueous humor dynamics: a review. Open Ophthalmol. J., v.4, p.52-59, 2010.

GRUS, F.H.; JOACHIM, S.C.; PFEIFFER, N. Proteomics in ocular fluids. Proteomics Clin. Appl., v.1, p.876-888, 2007. 
GUM, G.G.; MACKAY, E.O. Physiology of the eye. In: GELATT, K.N. (Ed.). Veterinary ophthalmology. 5ed. Philadelphia: Blackwell Publishers, 2013. p.183-192.

HAZEL, S.J.; THRALL, M.A.; SEVERIN, G.A. et al. Laboratory evaluation of aqueous humor in the healthy dog, cat, horse, and cow. Am. J. Vet. Res., v.46, p.657-659, 1985.

KROHNE, S.G.; KROHNE, D.T.; LINDLEY, D.M. et al. Use of laser flaremetry to measure aqueous humor protein concentration in dogs. $J$. Am. Vet. Med. Assoc., v.206, p.1167-1172, 1995.

LINN-PEARL, R.N.; POWELL, R.M.; NEWMAN, H.A. et al. Validity of aqueocentesis as a component of anterior uveitis investigation in dogs and cats. Vet. Ophthalmol., v.18, p.1-9, 2014.

MILLAR, J.C.; GABELT, B.T.; KAUFMAN, P.L. Aqueous humor dynamics. In: TASMAN, W. (Ed.). Duane's clinical ophthalmology. Philadelphia: Lippincott Williams \& Wilkins, 2006. CD Rom.

MUIR, W.W.; HUBBELL, J.A.E. Equine anesthesia: monitoring and emergency therapy. 2.ed. [Rio de Janeiro]: Saunders, 2009. 478p.

MUKAKA, M.M. A guide to appropriate use of correlation coefficient in medical research. Malawi Med. J., v.24, p.69-71, 2012.
SCHNEIDER, C.A.; RASBAND, W.S.; ELICEIRI, K.W. NIH Image to imageJ: 25 years of image analysis. Nat. Methods, v.9, p.671-675, 2012.

TELES, L.M.; AQUINO, E.N.; NEVES, A.C. et al. Comparison of the neutrophil proteome in trauma patients and normal controls. Protein Pept Lett., v. 19, p.663-672, 2012.

TOWNSEND, W.M. Canine and feline uveitis. Vet. Clin. Small Anim. Pract., v.38, p.323-346, 2008.

VAN DER WOERDT, A.; GILGER. B.C., WILKIE, D.A. et al. Effect of auriculopalpebral nerve block and intravenous administration of xylazine on intraocular pressure and corneal thickness in horses. Am. J. Vet. Res., v.56, p.155158, 1995.

WIGGANS, K.; VERNAU, W.; LAPPIN, M. et al. Diagnostic utility of aqueocentesis and aqueous humor analysis in dogs and cats with anterior uveitis. Vet. Ophthalmol., v.17, p.212220, 2014.

YOUNG, K.M. Ocular cytology: basic and advanced cães - 2 part. CONGRESSO INTERNAZIONALE MULTISALA, 56., 2007, Florence. Annali... Florence, Italy: SCIVAC, 2007. 